Cahiers $d u$ MONDE RUSSE

\section{Cahiers du monde russe}

Russie - Empire russe - Union soviétique et États indépendants

\title{
Gilles Favarel-Garrigues, La police des mœurs économiques de l'URSS à la Russie
}

\section{Alexis Spire}

\section{OpenEdition}

\section{Journals}

Édition électronique

URL : https://journals.openedition.org/monderusse/6973

DOI : 10.4000/monderusse. 6973

ISSN : $1777-5388$

Éditeur

Éditions de l'EHESS

\section{Édition imprimée}

Date de publication : 28 décembre 2008

Pagination : 792-794

ISBN : 978-2-7132-2197-2

ISSN : $1252-6576$

Référence électronique

Alexis Spire, «Gilles Favarel-Garrigues, La police des mœurs économiques de l'URSS à la Russie », Cahiers du monde russe [En ligne], 49/4 | 2008, mis en ligne le 24 décembre 2009, consulté le 03 septembre 2022. URL : http://journals.openedition.org/monderusse/6973 ; DOI : https://doi.org/ $10.4000 /$ monderusse. 6973

Ce document a été généré automatiquement le 3 septembre 2022.

Tous droits réservés 


\title{
Gilles Favarel-Garrigues, La police des mœurs économiques de l'URSS à la Russie
}

\author{
Alexis Spire
}

\section{RÉFÉRENCE}

Gilles FAVAREL-GARRIGUES, La police des mœurs économiques de l'URSS à la Russie.

Paris : Éditions du CNRS, 2007, 320 p. (Coll. « Mondes russes »).

1 En l'espace de quelques années, l'image politique de la Russie est passée du symbole de l'économie planifiée à l'archétype d'un État gangrené par la criminalité économique et la corruption. Cette forme de "transition démocratique ", commune à bien d'autres pays de l'ancien bloc de l'Est, mérite que l'on s'y arrête et qu'on la considère comme un fait social à part entière. C'est tout l'enjeu du livre de Gilles Favarel-Garrigues, qui s'intéresse à la régulation des pratiques économiques illicites des débuts de l'ère Brežnev au milieu des années 1990. Allant contre l'idée reçue d'une rupture radicale entre un pouvoir totalitaire et une ère marquée par le libéralisme, l'auteur démontre de façon très convaincante les continuités dans la conception et la mise en œuvre de la répression des illégalismes d'un régime à l'autre. L'essentiel de la démonstration repose sur l'analyse des rapports administratifs que les services répressifs de la région de Sverdlovsk adressèrent au parti communiste entre 1965 et 1991, complétée par des entretiens avec des agents encore en poste ou à la retraite. Il est d'ailleurs regrettable que les particularités géographiques, historiques et politiques de cette région ne soient pas davantage explicitées; l'absence de lexique, d'index et de chronologie rend plus difficile la compréhension des enjeux locaux et leur place par rapport au reste du pays.

2 Mais le livre de Favarel-Garrigues n'est pas seulement une contribution à l'histoire de la Russie. C'est aussi l'étude d'un mode spécifique de gestion des illégalismes, appréhendée à partir des usages du droit et des pratiques bureaucratiques. Dans le prolongement d'une 
littérature déjà abondante sur le rôle des street-level bureaucrats, il porte une attention particulière à l'activité des agents ordinaires qui, au niveau local, peuvent décider de sanctionner plus ou moins lourdement - ou même de laisser impunies - les infractions à l'ordre économique.

Récusant le découpage imposé par la chronologie traditionnelle, l'auteur entend dégager certaines continuités dans l'évolution de la criminalité économique et de sa gestion par le pouvoir. Dans un premier temps - des années 1970 à l'arrivée de Gorbatchev au pouvoir -, la figure du délinquant se décline selon trois catégories : parasites, récidivistes et alcooliques. En pratique, la plasticité de ces notions laisse une grande marge d'autonomie aux services répressifs qui les utilisent soit pour mieux atteindre leurs objectifs quantitatifs formulés en termes de taux d'élucidation (en attribuant par exemple une infraction à un coupable déclaré en fuite), soit pour moduler la sanction en fonction des ressources et de la position sociale du contrevenant (en privilégiant par exemple le traitement extrajudiciaire lorsqu'il s'agit d'un membre du parti). Une nouvelle période s'ouvre avec la perestroïka et l'avènement de la glasnost. À partir de 1986 , plusieurs lois successives transforment les règles du jeu économique : le statut de la propriété est modifié, l'activité de travail individuel est encouragée, les entrepreneurs obtiennent le droit de développer des activités commerciales avec l'étranger, les privatisations des magasins et des entreprises se généralisent. Dès lors, nombreux sont ceux qui n'ont plus aucun moyen de savoir si les revenus qu'ils tirent de la location d'un bien immobilier ou de telle autre activité sont considérés comme licites ou illicites. Cette incertitude sur la définition de la criminalité économique survient sur fond d'une véritable crise des institutions répressives, que l'auteur analyse en termes sociologiques, dans l'un des meilleurs chapitres de l'ouvrage. Manque de moyens, faiblesse des rémunérations et détérioration des conditions de travail génèrent un véritable malaise chez les agents du maintien de l'ordre. En 1989, plus de 80000 policiers démissionnent, dont beaucoup rejoignent le secteur privé ou coopératif. Or, si les agents spécialisés dans la lutte contre la criminalité économique perdent beaucoup de leurs moyens de contrôle, notamment la capacité d'accéder aux informations internes aux entreprises, la connaissance acquise au sein des institutions répressives devient un véritable capital susceptible d'être reconverti auprès des nouveaux propriétaires, d'autant que ceux-ci proposent des salaires en moyenne trois fois supérieurs à ceux de la fonction publique. Face à une telle hémorragie de ses troupes, l'État répond par une relance des recrutements, ce qui, à moyens constants, suppose d'abaisser le niveau de compétence exigé et d'être moins regardant sur la probité des candidats retenus. On comprend ainsi beaucoup mieux les conditions sociales dans lesquelles se réorganise le système policier du nouveau régime. On aurait aimé pourtant que cette fine analyse des institutions soit complétée par des entretiens approfondis restituant les trajectoires de quelques-uns de ces agents de l'État gagnés par le doute. Il n'en reste pas moins que la description des contradictions auxquelles se trouve confronté le nouveau pouvoir russe est des plus éclairantes: les dirigeants ne peuvent que constater l'affaiblissement des services répressifs, configuration propice au développement d'une nouvelle criminalité économique, elle-même génératrice de collusions entre agents administratifs et " entrepreneurs de violence». De surcroît, la transformation des règles du jeu économique s'accompagne à partir de 1991 d'un processus de dépénalisation d'infractions comme la spéculation ou la violation des règles du commerce, parachevé en 1996 par l'adoption d'un nouveau code pénal qui rompt avec la législation antérieure en plaçant la protection des personnes au-dessus de celle de l'État. 
En apparence, les institutions répressives russes ont connu en l'espace de quelques années d'importants bouleversements : les services de lutte contre les atteintes à la propriété socialiste sont devenus les services de lutte contre la criminalité économique et les anciennes figures $d u$ "hooligan» et du "parasite» ont cédé la place à celle, plus englobante, du "crime organisé ». Mais l'originalité de la thèse de Gilles FavarelGarrigues est de démontrer qu'au-delà de ces changements de façade, le lien entre le mode d'organisation de la bureaucratie policière et le comportement des agents est resté le même, ce qui a favorisé une certaine continuité des anciennes pratiques répressives. À tous les niveaux de l'administration, les agents reconvertissent leurs savoirs et leurs compétences pour faire face à leur nouvelle mission. Tout d'abord, les autorités fédérales ont maintenu le type de relation hiérarchique, les indicateurs d'activité et les modes d'évaluation qui prévalaient dans l'ancien régime. De plus, pour intensifier la lutte contre la nouvelle délinquance économique, elles ont continué à puiser dans le répertoire soviétique, en choisissant de lancer de grandes campagnes comme celle de 1991 contre le «sabotage économique». À l'échelon des cadres intermédiaires, l'obligation de se soumettre aux indicateurs chiffrés a continué à structurer l'ensemble de l'activité policière. Il en est d'ailleurs de même pour les services chargés des privatisations, qui avaient pour mission de rompre avec l'ordre économique mais qui devaient, pour y parvenir, se conformer à une politique du chiffre largement reprise de la planification soviétique. Mais c'est sans doute au niveau des street-level bureaucrats que la continuité des pratiques d'une période à l'autre est la plus frappante : focalisation sur les petits délits pour améliorer le taux d'élucidation, manipulation des catégories juridiques pour mieux coller aux indicateurs... L'idée d'une continuité dans la gestion différentielle des illégalismes est également très féconde, mais elle reste à un niveau de formulation trop théorique et ne se trouve guère étayée, ni par des exemples issus d'enquêtes empiriques ni par des dossiers individuels d'archives qui auraient permis d'en montrer la manifestation concrète. Au total, l'ouvrage nous vaut, au-delà des éclairages très stimulants sur l'histoire récente de la Russie, une contribution majeure à la compréhension du fonctionnement des États modernes et des rapports entre répression de la criminalité et usages du droit. 